\title{
CAX, JOINT TRAINING AND TRANSFORMATION OBJECTIVES
}

\section{Orlin NIKOLOV}

\begin{abstract}
This article elaborates on the issues related to improving joint training. Special emphasis is given to transformation of training and especially to the establishment of the Joint National Training Capability (JNTC) as the cornerstone of training transformation. The author presents the six functional areas of JNTC implementation: Joint Management Office, Joint Training System Application, Joint Command and Control, Opposing Forces, Joint Training Infrastructure, and Advanced Training Technologies. The role of modeling and simulation and CAX in particular is also discussed. The various challenges and approaches are presented in a global distributed training environment.
\end{abstract}

Keywords: Joint Training, Transformation, Joint National Training Capability, Modeling and Simulation, CAX.

"Effectiveness in combat will depend heavily on jointness, and how well the different branches of the military can communicate and coordinate their efforts on the battlefield ... Achieving jointness in wartime requires building that jointness in peacetime. We need to train like we fight and fight like we train and, too often, we don 't."

Donald H. Rumsfeld, US Secretary of Defense

\section{Introduction}

Establishing a Joint National Training Capability (JNTC) is considered a critical new tool in the efforts to transform training. This will significantly improve joint training by embedding joint tactical tasks in Service training events, closing horizontal gaps between Service training programs, establishing broader joint interoperability training events, and configuring exercises to improve vertical exercise linkages, all in a global distributed training environment.

The first transformation of training was the establishment and improvement of Service training centers. These sites provided the Services with robust, dynamic training 
in a realistic, albeit Service-centric, combat environment. The JNTC will produce a second transformation in training by extending the Service-centric focus to encompass joint operations. This will improve realism in a joint context, improve representation of opposing forces, improve ground truth through improved instrumentation and data sharing, and improve the assessment of joint training events.

The JNTC will reach beyond the essentials of training event planning and execution. JNTC will combine Service investments in training systems, infrastructure and Computer Assisted Exercises (CAX), such that the tools of training are joint tools. JNTC will ensure that all elements of joint command and control systems, processes, and techniques are employed in Service and joint training. JNTC will provide oversight and management for diverse, unique, and expensive Service Opposing Force (OPFOR) investments such that critical OPFOR tools can be shared across Service boundaries. JNTC will provide incentives to the Services to ensure that investments in training are joint and interoperable. Finally, JNTC will provide the resources, coordination, focus, and, a test-bed for the development and implementation of advanced training technologies and conducting CAX.

The JNTC is the cornerstone of training transformation creating a persistent joint training environment that enables Bulgarian (BG) forces to train like they fight, at an affordable cost.

\section{Solving the Program - Training Transformation}

Training in today's military must prepare the force to learn, improvise, and adapt to constantly changing threats in addition to executing doctrine to standards. Training transformation initiative is designed to provide dynamic, capability-based training in support of national security requirements and will accomplish the following objectives in conducting CAX:

- Strengthen joint operations by preparing forces for new war-fighting concepts;

- Continuously improve joint force readiness by aligning joint education and training capabilities and resources with combatant command needs;

- Develop individuals and organizations that intuitively think jointly;

- Develop individuals and organizations that improvise and adapt to emerging crises;

- Achieve unity of effort from a diversity of means.

The goal of establishing the JNTC is to improve the ability of BG forces to fight effectively as a joint and combined team by extending joint training to a much broader 
audience. There can be no question that Joint operations are essential for the future success of the BG military forces.

While the requirement for individual Services to train their units in core competencies will never go away, the need for a more extensive joint training experience, with the attendant supporting infrastructure, is clearly evident. If BG forces must be ready to fight jointly, with little or no notice, and in a complex and challenging situation presented by the $21^{\text {st }}$ century security environment, joint training must be institutionalized to a degree not seen before.

The JNTC will provide a setting, in which we can improve the readiness of BG forces to fight effectively as a joint and combined team.

Such an improvement requires a new set of capabilities to augment our existing training structure. These new capabilities must be built firmly upon, and integrated with, the already capable Service training centers and facilities, such as the simulations centers and the National Military Training Complex (NMTC). These facilities not only represent a considerable investment, but they have also excelled at training units in Service tactical competencies.

Achievement of the JNTC vision requires a careful transition that must be accomplished without interrupting force readiness. With this requirement in mind, the implementation of the JNTC plan is composed of two parallel efforts.

The first is an integration of existing Service and joint training events to steadily increase the joint dimension of the training environment. This could be done initially with organizing and participation in more joint national and international events like meetings, conferences, seminars, and CAX.

The second effort is to increase the degree of interoperability between Service and joint training facilities. This will be done initially in accordance with priorities established by the Commander, Joint Forces Command, in consultation with the Ministry of Defense (MoD). The goal is to create a joint, world-wide network of training capabilities using the full spectrum of live, virtual, and constructive environments.

As the JNTC matures, it will be available to serve additional purposes. The capabilities being built will prove useful for experimentation, concept development, testing and evaluation, rapid prototyping, mission rehearsal and the melding of all elements of national power. However, joint, combined, and interagency training, essential to success in future conflicts, is the primary purpose for investing in this capability. 


\section{JNTC - The Concept}

\section{Six Functional Areas}

JNTC is significantly more complex than simply a capability to plan and execute Joint training events. The implementation of the JNTC has six focal areas organized primarily by function. They include the Joint Management Office, the Joint Training System Application, Joint Command and Control, Opposing Forces, Joint Training Infrastructure, and Advanced Training Technologies.

Joint Management Office (JMO)

JMO is established to oversee the programs and processes necessary to implement the JNTC.

The JNTC JMO will analyze Combatant Command requirements and warfighter capabilities to establish training methods and technologies that enable forces to train like they fight across the full spectrum of warfighter tasks.

\section{Joint Training System Applications (JTSA)}

Through the application of the JTS, exercises will be designed to ensure Combatant Commanders' and Service requirements are mutually developed through a detailed planning, execution, and assessment process. Furthermore, standards and conditions will be developed for the joint tactical tasks, and exercises will be more focused on operational mission needs. Finally, a capability improvement process will be implemented to develop and incorporate joint tactical tasks into training events and assessments.

\section{Joint Command and Control (JC2)}

A joint command-and-control concept of operations will be developed to ensure that the appropriate joint headquarters is represented in joint events. To provide standardized training for the future Command-and-Control activity, will supply a distributed training capability immersed in a multilevel security environment. Command and control equipment, as well as joint tactics, techniques, and procedures will be used to enable the continuous development of transformational concepts for export to Service training ranges and events.

\section{Opposing Forces (OPFOR)}

Planning and execution of fully coordinated live and virtual opposing forces in support of joint events will be centralized under Joint Forces Command. A standing opposing force headquarters will be activated to provide the core organization to plan, schedule, and integrate opposing forces for JNTC supported events. Funding for threat systems used in joint events will improve existing Service training ranges and areas and will provide the appropriate threat representation to the training audience. 


\section{Joint Training Infrastructure (JTI)}

Joint Forces Command will establish a joint training communications infrastructure to support JNTC events. The communications structure will use the Global Information Grid and other existing networks provided by MoD and other agencies. Where necessary, funds will be provided to extend the network out to training areas and ranges where inadequate connectivity presently exists. The infrastructure will adhere to common industrial standards to ensure interoperability and compatibility among JNTC locations. It will be persistent and rapidly reconfigurable to establish the necessary links to support JNTC events. Architecture and standards are required to enable joint, distributed training across simulation centers. The National Military Training Complex will integrate and test systems to be used at JNTC-supported events. Research and development will support the analysis and development of specific JNTC infrastructure capabilities, including advances in communications, interoperability, image generation, data transfer, video transfer, and range instrumentation. Procurement of command-and-control systems; communications; audio, visual, simulation, and knowledge management systems; and range instrumentation is essential to achieve the infrastructure objectives. This instrumentation must be mobile to support remote exercises.

\section{Advanced Training Technologies}

Advanced training technologies will be developed to effectively integrate live, virtual, and constructive elements into a seamless joint environment. As advanced training technologies are developed, they will be integrated into JNTC-supported events. A test-and-integration test bed will be established to validate live, virtual, and constructive interoperability across a distributed network of ranges and facilities. In addition, a robust research, development, and demonstration program should be established to ensure that the latest science and technologies are incorporated quickly into defense knowledge superiority capabilities, as well as into globally distributed mission rehearsal and joint training systems. The test and evaluation community may exploit the JNTC to support its events.

\section{JNTC - Implementation}

To define, build, implement, and maintain the system and technical architecture to support the operational training concepts of the JNTC, a well-structured and defined systems engineering and configuration management process should be created and managed. The JNTC system and technical architecture should be composed of models and simulations, simulators, communications infrastructure, command and control systems, range instrumentation systems, and emerging training technology systems. Research, design, development, integration, test, and operation of the technical infra- 
structure should be accomplished trough the technical management of various activities with Joint Forces Command, the Services, and contractor support organizations.

Conducting exercises, although a complex combination of human participants, real systems and equipment as well as models and simulations, would significantly enhance the readiness and Joint warfighting capabilities of the participants.

The objective is to provide a training venue that enhances our ability to improve Joint warfighting capabilities. Today we can operate jointly, but only with great effort to overcome the warfighting gaps. As the force transforms, we must achieve jointness in peacetime so that we can achieve full spectrum dominance in times of conflict. In other words, the force of the future must be born Joint - our doctrine, organizations, training, material, leaders, personnel and facilities must all be interoperable. JNTC will provide broad-based management for $\mathrm{MoD}$ training transformation resources.

"Effectiveness in combat will depend heavily on jointness, and how well the different branches of the military can communicate and coordinate their efforts on the battlefield ... (A)chieving jointness in wartime requires building that jointness in peacetime." As the "centerpiece of training transformation," the JNTC will ensure that we can "train like we fight and fight like we train." 


\section{References:}

1. Howard W. Thorp and Gregory F. Knapp, "The Joint National Training Capability 'The Centerpiece of Training Transformation'” (paper presented at the Interservice/ Industry Training, Simulation, and Education Conference (I/ITSEC), 2003), <www.simsysinc.com/I_ITSEC_2003_JNTC1a.pdf> (12 October 2007).

2. John J. Walsh, Office of the Deputy Under Secretary of Defense (Readiness), "Joint National Training Center," (paper presented at the $40^{\text {th }}$ Annual NDIA Air Targets, UAVs Range Operations Symposium and Exhibition, 2-3 October 2002), <http://www.dtic.mil/ndia/2002targets/walsh.pdf> (12 October 2007).

3. John Woods, Technical Director, Joint Warfighting Center, "The Joint National Training Capability - An Overview," <www.mors.org/meetings/training/ presentations/Woods.pdf> (12 October 2007).

4. Concept for Development of National Center for Modeling and Simulations.

ORLIN NIKOLOV is Lieutenant Colonel in the Bulgarian Armed Forces. In 1991 he graduated the Higher Artillery and Air Defense School in Shumen, Bulgaria, and in 2003 - the Command and Staff Course of the "G.S. Rakovski" Defense and Staff College in Sofia, Bulgaria. He has served on a variety of positions in air defense units and in the National Military Modeling and Simulation Center. Currently LTC Nikolov serves as Deputy Chief of Section in the Joint Training (J7) Department of the General Staff of the Bulgarian Armed Forces. In a number of publications in refereed journals he deals with the challenges of air defense, computer-assisted exercises, and other important transformation topics. 